\title{
Assessment of Cocoon and Egg Productivity in Selected Strains of Eri Silkworm through Consumption and Utilization Indices
}

\author{
B.K. Prakash ${ }^{1}$, B. Sannappa ${ }^{2 *}$ \\ ${ }^{1,2}$ Dept. of Studies in Sericulture Science, University of Mysore Manasagangotri, Mysuru - 570 006, India \\ *Corresponding Author: E-mail: drbsannappa@gmail.com, Tel: +91-9448614385
}

Available online at: www.isroset.org

Received: 10/Nov/2018, Accepted: 12/Dec/2018, Online: 31/Dec/2018

\begin{abstract}
Silkworm nutrition deals with the substances required for growth and production of proteinaceous silk fiber. The quantum of food consumption, utilization and conversion efficiency into body mater for production of silk mainly governed by the type of host/variety on which silkworm feeds and also strain/breed of silkworm. In the current investigation, selected eri silkworm (Samia cynthia ricini Boisduval) strains (Blue-Plain, Blue-Zebra, Blue Greenish-Plain, White-Plain, White-Zebra, Yellow-Plain, Yellow-Spotted and Yellow-Zebra) were reared using Local Pink castor leaf to assess the efficiency of ingestion, digestion and conversion of food for production of unit quantity of cocoon, shell and eggs. The study revealed that, among the eri silkworm strains White-Plain larvae exhibit significantly least ingesta and digesta to produce a gram of cocoon and shell and it was more with White-Zebra both on fresh and dry weight basis, respectively. The efficiency of conversion of ingested food and digested food into cocoon and shell both on fresh and dry weight basis was significantly better with White-Plain, least values were found with Blue-Plain and Yellow-Spotted for ingested food and digested food, respectively. In respect of leaf-egg ratio, White-Plain strain stood best over other strains with least being in Yellow-Zebra strain. The study inferred that, WhitePlain strain of eri silkworm performed better by recording higher efficiency in consumption and utilization of food for eri cocoon and egg production.
\end{abstract}

Keywords: Consumption, Eri silkworm, Indices, Samia cynthia ricini, Strains.

\section{INTRODUCTION}

Insects, like all other living organisms, require nutrients to survive, grow and reproduce. The nutrients (proteins, carbohydrates, fats, minerals and vitamins) in the food are digested and absorbed at different degrees depending on the silkworm breed, host plant variety and environmental conditions [1]. Almost all insects are host specific and select their most preferred food in order to extract the maximum benefit out of it, although most of them eat a great many varieties [2]. Different food plants may influence differently on food intake, efficiency of digestion and conversion of food to body biomass and finally on growth and development of insect [3].

Nutritional indices as well as growth and development of insect varied on different hosts. Generally varieties of the some species may exert variable effect on the relative survival of herbivore insect. The nutrition that an insect derives during the course of development plays a significant role in its commercial exploitation. The process of consumption, digestion and conversion efficiency in its broader sense underlines the physiological, behavioral, ecological and evolutionary aspects of insect life [4]. The suitability of host is determined through estimation of rate of ingestion, digestibility, conversion efficiency of food and growth rate of the animal [5].

In insects, consumption and utilization of food facilitate the understanding of the adaptability of insects. Female insects have generally lower consumption and higher conversion of food into body matter. Difference in food consumption and conversion into body matter has been understood among silkworm breeds quite early. The inferior growth expressed by the tropical races compared with the temperate races may be due to low consumption rate, nutritional inadequacy and a combination of both [3].

Among many factors attributed for silk production, the major one being the nutritional efficiency, as it has direct impact on the overall performance of economic characters of silkworm such as larval and cocoon weights, amount of silk production, pupation and reproductive traits [6]. Insects feed on a remarkably diverse number of organic substances. Even so, most species show a great degree of specificity in food selection and feeding. Competition and natural selection gradually drive and bind each insect species to a specialized food supply that it can utilize more efficiently than its competitors [7]. 
Food intake and conversion efficiency play a pivotal role in converting leaf substances into silk. Further, many factors determine the food intake, digestion and conversion efficiency of silkworm. Ingestion of equal amounts of leaves under different feeding and nutritional conditions impacts silkworm nutrition and silk synthesis [8]. The literature pertaining to the consumption, utilization and conversion of food per unit quantity for production of silk and egg is meager. In this regard, a research work has been undertaken to understand the relationship between food intake, digestion and food conversion efficiency vis-a-vis the production of cocoon and eggs in selected strains of eri silkworm.

\section{MATERIALS AND METHODS}

\section{Pre-rearing operations}

Disinfection is an integral part of silkworm rearing, as eri silkworm has been reared under indoor conditions which lead to accumulation of disease causing germs in the rearing environment. In this regard, as a precautionary measure, rearing house was disinfected with $0.05 \%$ of Asthra @ 2.0 $1 / \mathrm{m}^{2}$. Disease free layings of eight strains of eri silkworm (Blue-Plain, Blue-Zebra, Blue Greenish-Plain, White-Plain, White-Zebra, Yellow-Plain, Yellow-Spotted and YellowZebra) was procured from the Central Sericultural Germplasm Resources Centre, Hosur and incubated at a temperature of $25 \pm 1^{\circ} \mathrm{C}$ and relative humidity of $75 \pm 5 \%$.

\section{Rearing operations}

The eggs (five DFLs) were black boxed on the day of pin head stage (8/9 day post-oviposition) to ensure uniform hatching. On the day of hatching, the eggs were exposed to diffused light at 8.00 AM for two hours. Rearing was conducted in the caged condition by feeding the leaves of Local Pink (Ricinus communis L.) castor leaf from the day of brushing till cocoon spinning. One hundred larvae in three replicates for each strain were maintained throughout the rearing period by replacing the missing larvae with the fresh ones for determination of consumption of utilization indices both on fresh and dry weight basis by gravimetric method [3, 9, 10, 4]. Left over (uneaten) leaves and excreta were collected in each instar and dried in a hot air oven daily at about $100^{\circ} \mathrm{C}$ until a constant weight was reached. When the larvae stopped feeding in the final (fifth) instar, they were allowed to spin cocoons at $25 \pm 2^{\circ} \mathrm{C}$ and $65 \pm 5 \% \mathrm{RH}$. Cocoons were assessed after harvest for cocoon weight, shell weight and shell ratio and in addition fecundity was also recorded in different strains of eri silkmoths.

\section{Determination of conversion efficiency of food}

1. Ingesta per gram of cocoon (g) (Leaf - cocoon ratio): The total ingesta required for the production of one gram of cocoon.

$$
\mathrm{I} / \mathrm{g} \text { cocoon }=\frac{\text { Weight of ingesta }(\mathrm{g})}{\text { Weight of cocoon }(\mathrm{g})}
$$

2. Ingesta per gram of shell (g) (Leaf - shell ratio): The total ingesta required for the production of one gram of shell.

$$
\mathrm{I} / \mathrm{g} \text { shell }=\frac{\text { Weight of ingesta }(\mathrm{g})}{\text { Weight of shell }(\mathrm{g})}
$$

3. Digesta per gram of cocoon (g): The total digesta required for the production of one gram of cocoon.

$$
\mathrm{D} / \mathrm{g} \text { cocoon }=\frac{\text { Weight of digesta }(\mathrm{g})}{\text { Weight of cocoon }(\mathrm{g})}
$$

4. Digesta per gram of shell (g): The total digesta required for the production of one gram of shell.

$$
\mathrm{D} / \mathrm{g} \text { shell }=\frac{\text { Weight of digesta }(\mathrm{g})}{\text { Weight of shell }(\mathrm{g})}
$$

5. Efficiency of conversion of ingesta to cocoon (Leaf cocoon conversion rate): It was the expression of efficiency conversion of ingesta into cocoon, also referred to as the leaf-cocoon conversion rate.

$$
\text { ECI }-\operatorname{cocoon}(\%)=\frac{\text { Weight of } \operatorname{cocoon}(\mathrm{g})}{\text { Weight of ingesta }(\mathrm{g})} \times 100
$$

6. Efficiency of conversion of ingesta to shell (Leaf - shell conversion rate): This was the expression efficiency of conversion of ingesta into shell. It is also referred to as the leaf-shell conversion rate and is the ultimate index to evaluate superiority of strain for nutritional efficiency.

$$
\text { ECI }- \text { shell }(\%)=\frac{\text { Weight of shell }(\mathrm{g})}{\text { Weight of ingesta }(\mathrm{g})} \times 100
$$

7. Efficiency of conversion of digesta to cocoon: The expression of efficiency of conversion of digesta into cocoon.

$$
\text { ECD }-\operatorname{cocoon}(\%)=\frac{\text { Weight of } \operatorname{cocoon}(\mathrm{g})}{\text { Weight of digesta }(\mathrm{g})} \times 100
$$

8. Efficiency of conversion of digesta to shell: The expression of efficiency of conversion of digesta into shell.

$$
\text { ECD }- \text { shell }(\%)=\frac{\text { Weight of shell }(\mathrm{g})}{\text { Weight of digesta }(\mathrm{g})} \times 100
$$

9. Leaf - egg ratio: The expression of efficiency of conversion of food consumed to number of eggs laid by the moth.

$$
\text { Leaf }- \text { egg ratio }=\frac{\text { Avg. fecundity of moth (eggs/laying) }}{\text { Avg. weight of food consumed }(g)}
$$

Statistical analysis of the data 
The data obtained in the current investigation was subjected to one-way ANOVA for test of significance $(p \leq 0.05$ and $p$ $\leq 0.01$ ) [11] through SPSS statistical package (ver. 21.0).

\section{RESULTS}

The results pertaining to consumption, digestion and conversation efficiency of food into cocoon, shell and egg production in selected strains of eri silkworm are illustrated in the form of graphs and are explained in the following pages:

\section{Ingesta/g of cocoon}

Quantity of food required for the production of one gram of cocoon could vary considerably among the strains of eri silkworm with least amount of food was registered with White-Plain strain (8.353 and 4.301g) over other strains namely Blue-Zebra (8.553 and 4.546g), Yellow-Plain (8.727 and $4.699 \mathrm{~g}$ ), Yellow-Spotted (8.871 and 5.204g), Blue-Plain (9.039 and 5.443g), Yellow-Zebra (9.066 and 5.412g) and Blue Greenish-Plain (9.108 and 5.428g) both on fresh and dry weight basis. However, more amount of food was consumed by White-Zebra strain (9.291 and 5.563g) (Fig. $1)$.

\section{Ingesta/g of shell}

White-Plain strain of eri silkworm took significantly less quantity of food (53.32 and $24.32 \mathrm{~g}$ ) to produce one gram of shell and the strains Blue-Zebra (54.85 and 25.89g), YellowPlain (56.32 and 27.26g), Yellow-Spotted (60.45 and $34.72 \mathrm{~g}$ ), Yellow-Zebra (60.46 and 33.88g), Blue GreenishPlain (60.91 and 34.26g), White-Zebra (61.36 and 33.77g) and Blue-Plain (62.13 and 37.64g) stood next in the order with latter strain took more amount of food both on fresh and dry weight basis, respectively (Fig. 2).

\section{Digesta/g of cocoon}

Digesta per gram of cocoon differed significantly with least amount being in White-Plain $(5.675 \mathrm{~g})$ followed by BlueZebra $(5.730 \mathrm{~g})$, Yellow-Plain $(5.837 \mathrm{~g})$, Blue-Plain $(6.017 \mathrm{~g})$, Yellow-Zebra (6.067g), Yellow-Spotted (6.085g) and Blue Greenish-Plain (6.088g). However, digesta per gram of cocoon were higher in White-Zebra $(6.215 \mathrm{~g})$ on fresh weight basis. On dry weight basis, digesta/g of cocoon was better with White-Plain strain (1.545g) when compared to BlueZebra (1.620g), Yellow-Plain (1.670g), White-Zebra $(1.846 \mathrm{~g})$, Blue Greenish-Plain (1.858g), Yellow-Zebra $(1.878 \mathrm{~g})$, Blue-Plain strains $(1.895 \mathrm{~g})$ and it was least with Yellow-Spotted strain (1.911g) (Fig. 3).

\section{Digesta/g of shell}

Quantum of food digestion differed significantly among the strains of eri silkworm with least value being in White-Plain strain (36.22g) over Blue-Zebra (36.75g), Yellow-Plain $(37.67 \mathrm{~g})$, Yellow-Zebra $(40.46 \mathrm{~g})$, Blue Greenish-Plain (40.71g), White-Zebra (41.07g), Blue-Plain strains (41.35g), while the amount of food digestion was higher with YellowSpotted strain $(41.46 \mathrm{~g})$ on fresh weight basis. In respect of dry weight basis, digesta/g of shell was significantly less with White-Plain strain $(8.731 \mathrm{~g})$ followed by Blue-Zebra (9.227g), Yellow-Plain (9.687g), White-Zebra (11.22g), Blue Greenish-Plain (11.73g), Yellow-Zebra (11.75g), Yellow-Spotted (12.75g) and it was more in Blue-Plain strain (13.11g) (Fig. 4).

\section{Efficiency of conversion of ingesta to cocoon}

Among the selected strains of eri silkworm, efficiency of conversion of ingesta to cocoon was significantly higher in White-Plain strain (11.98\%) followed by Blue-Zebra (11.69\%), Yellow-Plain (11.46\%), Yellow-Spotted (11.28\%), Blue-Plain (11.06\%), Yellow-Zebra (11.03\%), White-Zebra strains $(10.76 \%)$ and it was lower with Blue Greenish-Plain strain $(10.98 \%)$ on fresh weight basis. On dry weight basis, efficiency of conversion of ingesta to cocoon was higher with White-Plain strain $(23.31 \%)$ and the strains Blue-Zebra (22.00\%), Yellow-Plain (21.28\%), Yellow-Spotted (19.28\%), Yellow-Zebra (18.48\%), Blue Greenish-Plain (18.44\%), Blue-Plain (18.38\%) and WhiteZebra strains $(18.00 \%)$ followed next in the order with latter being the least (Fig. 5).

\section{Efficiency of conversion of ingesta to shell}

Efficiency of conversion of ingesta to shell was significantly higher in White-Plain strain $(1.876 \%)$ followed by BlueZebra (1.824\%), Yellow-Plain (1.776\%), Yellow-Spotted (1.654\%), Blue Greenish-Plain (1.642\%), White-Zebra strains $(1.630 \%)$ and it was lower with Blue-Plain strain $(1.612 \%)$ on fresh weight basis. With respect to dry weight basis, efficiency of conversion of ingesta to shell was better with White-Plain strain $(4.113 \%)$ when compared to BlueZebra (3.869\%), Yellow-Plain (3.677\%), White-Zebra $(2.964 \%)$, Yellow-Zebra (2.953\%), Blue Greenish-Plain $(18.44 \%)$ and Yellow-Spotted strains $(2.884 \%)$, it was least with Blue-Plain strain (2.687\%) (Fig. 6).

\section{Efficiency of conversion of digesta to cocoon}

Among the different strains of eri silkworm, efficiency of conversion of digesta to cocoon was significantly better with White-Plain strain (17.63\%) as compared to Blue-Zebra (17.45\%), Yellow-Plain (17.13\%), Blue-Plain (16.62\%), Yellow-Zebra (16.48\%), Yellow-Spotted (16.45\%) and Blue Greenish-Plain strains $(16.43 \%)$ and it was inferior with White-Zebra strain $(16.09 \%)$ on fresh weight basis. When scored on dry weight basis, efficiency of conversion of digesta to cocoon was superior with White-Plain strain $(64.96 \%)$ followed by Blue-Zebra $(61.75 \%)$, Yellow-Plain $(59.88 \%)$, White-Zebra $(54.20 \%)$, Blue Greenish-Plain $(53.86 \%)$, Yellow-Zebra $(53.26 \%)$ and Blue-Plain strains $(52.78 \%)$. However, it was found inferior with YellowSpotted strain (52.49\%) (Fig. 7).

\section{Efficiency of conversion of digesta to shell}


In respect of efficiency of conversion of digesta to shell, eri silkworm strains differed notably with significantly superior value was found with White-Plain strain $(2.761 \%)$ followed by Blue-Zebra $(2.722 \%)$, Yellow-Plain $(2.655 \%)$, YellowZebra $(2.472 \%)$, Blue Greenish-Plain (2.456\%), WhiteZebra $(2.437 \%)$ and Blue-Plain strains $(2.421 \%)$ and it was inferior with Yellow-Spotted strain $(2.412 \%)$ on fresh weight basis. With respect to dry weight basis, efficiency of conversion of digesta to shell was significantly better with White-Plain strain (11.46\%) over Blue-Zebra (10.86\%), Yellow-Plain (10.34\%), White-Zebra (8.932\%), Blue Greenish-Plain (8.530\%), Yellow-Zebra (8.512\%) and Yellow-Spotted strains $(7.854 \%)$ and the same was least with Blue-Plain strain (7.721\%) (Fig. 8).

\section{Leaf - egg ratio}

Leaf - egg ratio too differed significantly among the eight strains of eri silkworm with higher value being in WhitePlain strain (1: 11.96) followed by Blue Greenish-Plain (1: 11.37), Blue-Zebra (1: 11.35), Yellow-Plain (1: 11.26), White-Zebra (1: 11.05), Blue-Plain (1: 10.89) and YellowSpotted strains (1: 10.13) and it was lower with YellowZebra strain (10.04) on fresh weight basis. On dry weight basis, leaf - egg ratio was more in White-Plain strain (1: 64.42) over Blue-Zebra (1: 61.38), Yellow-Plain (1: 59.50), Blue Greenish-Plain (1: 59.84), White-Zebra (1: 59.02), Blue-Plain (1: 58.17), Yellow-Spotted strains (1: 55.47) and the value was less with Yellow-Zebra strain (1: 53.24) (Fig. 9).

\section{DISCUSSION}

The ingestion, digestion and conversion efficiency of food in commercial insect like silkworm is of greater significance as it indicates the quantum of food uptake and their utilization for the production of silk/eggs. Variations were evident among the strains of eri silkworm in utilization of castor leaf for the production of unit quantity of eri cocoon and eggs. Conversion efficiency of ingesta to larva, cocoon and shell were highest and the grams of ingesta necessary to produce one gram of cocoon and silk shell were the lowest, indicating that the larval enzymatic apparatus were used to convert nutrients to body matter and more specifically to silk proteins [6].

The variation in leaf-cocoon and egg ratio was evident among the castor genotypes when their leaf was offered as food [12, 13]. Similarly, higher LCR on Aruna castor both for food offered and consumed, followed by SH-41 and it was lower on Local genotype [13]. The trend was similar on dry weight basis both for food offered and consumed. Further, variation in leaf - cocoon and silk conversion rate of eri silkworm were recorded when different castor genotypes were offered to eri silkworms [14].
Eri silkworms fed on leaves of DCS-85 registered less leafcocoon ratio (11.13:1), while leaf-egg ratio was least with GCH4 (8.110:1). Whereas, Genotype DCH-85 recorded higher leaf-cocoon conversion rate $(8.987 \%)$ along with DCH-171 (8.773\%), while leaf-silk conversion rate was more with Local genotype (1.110\%) together with DCS-85 $(1.093 \%)$ and DCH-171 (1.080\%). On the other hand, both leaf-cocoon and silk conversion rates were least with $\mathrm{GCH}-4$ genotype (6.853 and $0.813 \%)$. Growth index (\% moth emergence) was highest with Local genotype (2.149). Further, net reproductive rate was higher with DCS-85 genotype (150.79) closely followed by Local (150.03) and 48-1 genotypes (148.34) [15].

The larval, cocoon and grainage indices, larval weight, cocoon weight, silk, eclosion and oviposition indices, leaf cocoon ratio, leaf - cocoon conversion rate, growth index $(\%$ pupation) and net reproductive rate were superior with DCS85; pupal weight index with DCS-9; larval, pupal, and larval - pupal duration indices with Kranti, DCH-177, DCS-85 and local; hatching index with DCS-9, DCS-85 and local; while leaf egg ratio was better with $\mathrm{GCH}-4$ [16].

Eri larvae fed on the leaves of DCH-519 castor hybrid recorded least ingesta and digesta to produce a gram of cocoon and shell. The efficiency of conversion of ingested and digested food into cocoon and shell on both fresh and dry weight basis was similar. With regard to leaf-laying ratio, eri moths resulting from the larvae offered with local green variety showed distinct superiority when compared with other castor hybrids / varieties. However, it was greater with DCH-519 on fresh weight and 48-1 variety on dry weight basis [17].

The current results mainly focuses on the screening of selected strains of eri silkworm for cocoon and egg production through their consumptive and conversion efficiency pattern and that of previous researchers were mainly confined to screening of castor genotypes/varieties/hybrids through conversion efficacy of food in eri silkworm. In both the types of investigation, greater amount of variation could be observed in ingestion and conversion efficiencies of food for the production of cocoon and eggs.

\section{CONCLUSION AND RECOMMENDATION}

The findings of the current study revealed that, White-Plain strain of eri larvae has consumed significantly less quantum of food to produce a gram of cocoon (8.353 and 4.301) and shell (5.675 and 1.545) on fresh and dry weight basis, respectively. Further, similar trend was observed for digesta (53.32, 24.32 and $36.22,8.731)$, efficiency of conversion of ingesta $(11.98,23.31$ and $17.63,64.96)$ and efficiency of conversion of digesta $(1.876,4.113$ and $2.761,11.46)$ for production of one gram of cocoon and shell. Even for leaf- 
egg ratio, White-Plain strain showed superiority over other strains (1: 11.96 and 1: 64.42) both on fresh and dry weight basis, respectively. From the foregoing account, it is pertinent that food conversion efficiency showed considerable variation among selected strains of eri silkworms with superior performance by White-Plain for the production of cocoon, shell and eggs. Thus, White-Plain strain could be conveniently used for rearing purpose in order to harvest better cocoon crop.

\section{ACKNOWLEDGMENT}

First author is thankful to the University Grants Commission, New Delhi, for financial assistance through Rajiv Gandhi National Fellowship for Ph.D. programme and both the authors are thankful to the Chairman, Department of Studies in Sericulture Science, University of Mysore, Mysuru, for providing the necessary facilities to carry out this study.

\section{REFERENCES}

[1]. L. Richard and Lindroth, "The food conversion efficiencies of insects herbivores". The Food Insect Newsletter, University of Wisconsin, Madison, Wiscons, 6 (1): 12, 1993.

[2]. C.T. Brues, “Insect Dietary”, Cambridge Mass, pp: 466, 1946.

[3]. G.P. Waldbauer, "The consumption and utilization of food by insects". Recent Adv. Insect Physiol., 5: 29-288, 1968.

[4]. F. Slansky and J.M. Scriber, "Food consumption and utilization". In: Comprehensive Insect Physiology, Biochemistry and Pharmacology. Pergamon Press, Oxford, 4: 88-151, 1985.

[5]. Englemann, "Energetics, terrestrial, field studies and animal productivity", In: Advances in Ecological Research (Ed. J.B. Cragg). Academic Press, London and New York, 3: 73-115, 1966.

[6]. V.K. Rahmathulla, M.T. Himantharaj, G. Srininvasa and R.K. Rajan, "Association of moisture content in mulberry leaf with nutritional parameters of bivoltine silkworm (Bombyx mori L.). Acta Entomologica Sinica, 47: 701-704, 2004.

[7]. V.K. Rahmathulla and H.M. Suresh, "Seasonal variation in food consumption, assimilation, and conversion efficiency of Indian bivoltine hybrid silkworm, Bombyx mori L.", Journal of Insect Science, 12: 82, 2012.

[8]. Y.S. Reddy, "Role of nutrition in silkworm (Bombyx mori L.) and cocoon production - A review”, J. Seric Tech., 2(1): 1-23, 2011.
[9]. J.M. Scriber and P. Feeny, "Growth of herbivorous caterpillars in relation to feeding specialization and to the growth form of their food plant", Ecology, 60: 829-850, 1979.

[10]. M. Kogan and J.R.P. Parra, "Techniques and applications of measurements of consumption and utilization of feed by phytophagous insects. In: Current Topics in Insect Endocrinology and Nutrition, Plenum Press, New York, pp. 337-352, 1981.

[11]. N. Sundarraj, S. Nagaraju, M.N. Venkataramu and M.K. Jagannath, "Design and Analysis of Field Experiments. Directorate of Research, UAS, Bangalore, p. 419, 1972.

[12]. D.N.R. Reddy and K.C. Narayanaswamy, "Effect of host on the consumption rate, leaf-cocoon and leaf-egg ratio of eri silkworm, Samia cynthia ricini Boisduval. Entomon, 24: 67-70, 1999.

[13]. B. Sannappa, M. Jayaramaiah, D.N.R. Reddy, S.S. Chavan and Rangaswamy, "Consumption and leaf - cocoon ratio of eri silkworm on castor genotypes. Proc. Natl. Sem. Tropic. Seric. UAS, Bangalore, 3: 47-49, 2000.

[14]. M. Jayaramaiah and B. Sannappa, "Influence of castor genotypes on cocoon traits and reproductive potential in eri silkworm, Samia cynthia ricini Boisduval (Lepidoptera: Saturniidae). Proc. XIX ${ }^{\text {th }}$ Cong. Int. Seric. Commission, 21-25 ${ }^{\text {th }}$ September, Bangkok, Thailand, pp. 256-260, 2002.

[15]. D. Chandrappa, "Performance of eri silkworm on some castor genotype and economics of ericulture-cum-castor seed production. Ph.D. Thesis, UAS, Bangalore, p. 146, 2003.

[16]. S. Chandrashekhar, "Identification of suitable castor genotypes for dual purpose of ericulture and seed production, Ph.D. Thesis, UAS, Bangalore, 122, 2007.

[17]. B. Sannappa, D. Manjunath and B.K. Prakash, "Efficacy of castor hybrids and varieties on nutritional efficiency in eri silkworm (Samia cynthia ricini Boisduval). Journal of Sericulture \& Technology, 4(1\&2): 27-34, 2013.

\section{AUTHORS PROFILE}

B.K. Prakash holds Post-Graduate degree in Sericulture and Seri-biotechnology and currently pursuing Ph.D. in Sericulture in the Department of Studies in Sericulture Science, University of Mysore, Manasagangotri, Mysuru and published six research papers in reputed journals. Dr. B. Sannappa is currently working as Assistant Professor in the Department of Studies in Sericulture Science, University of Mysore, Manasagangotri, Mysuru, published well over 50 research papers in reputed journals and successfully guided three research candidates leading to Ph.D. Degree in Sericulture. 


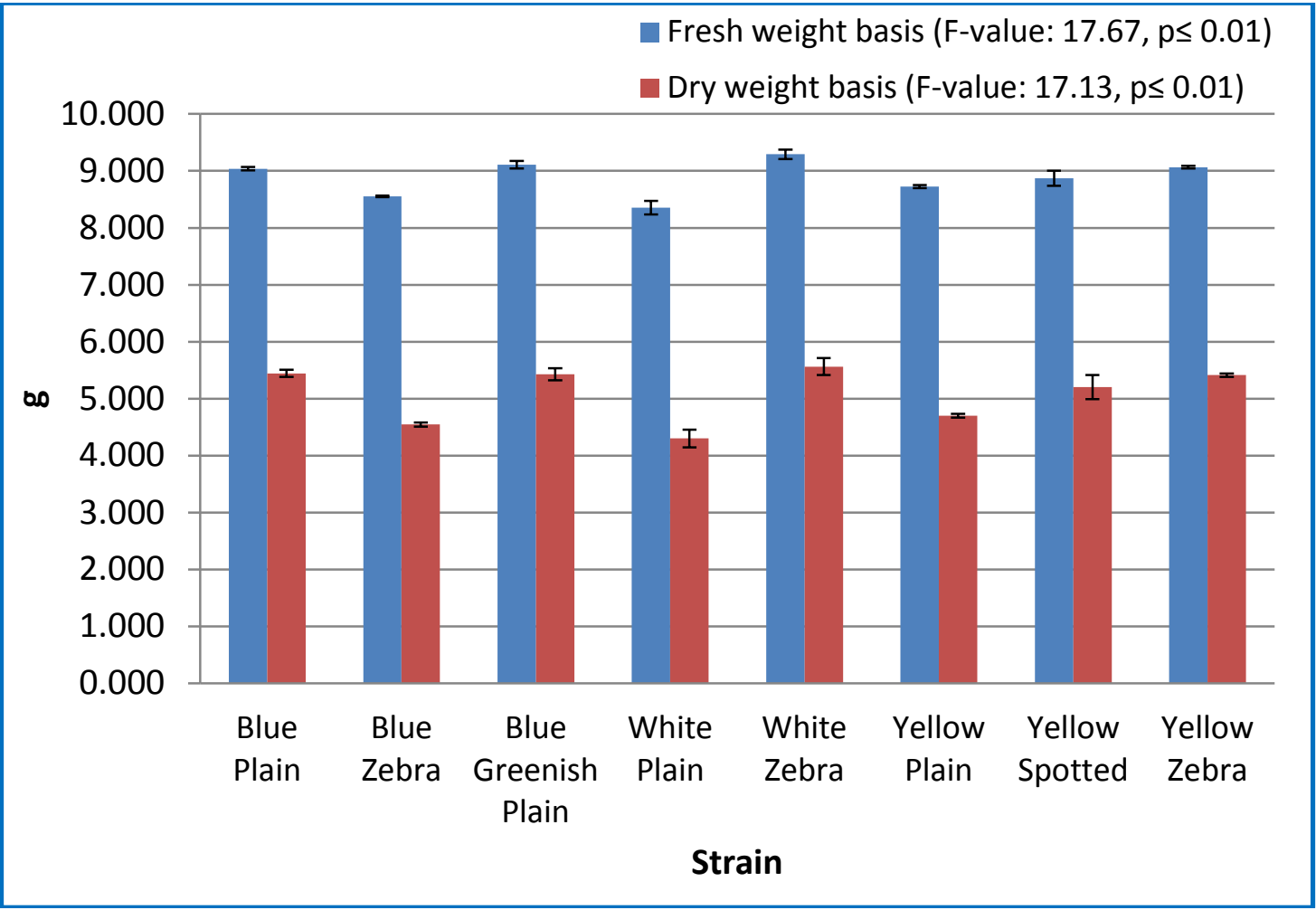

Fig. 1: Ingesta per gram of cocoon in selected strains of eri silkworm

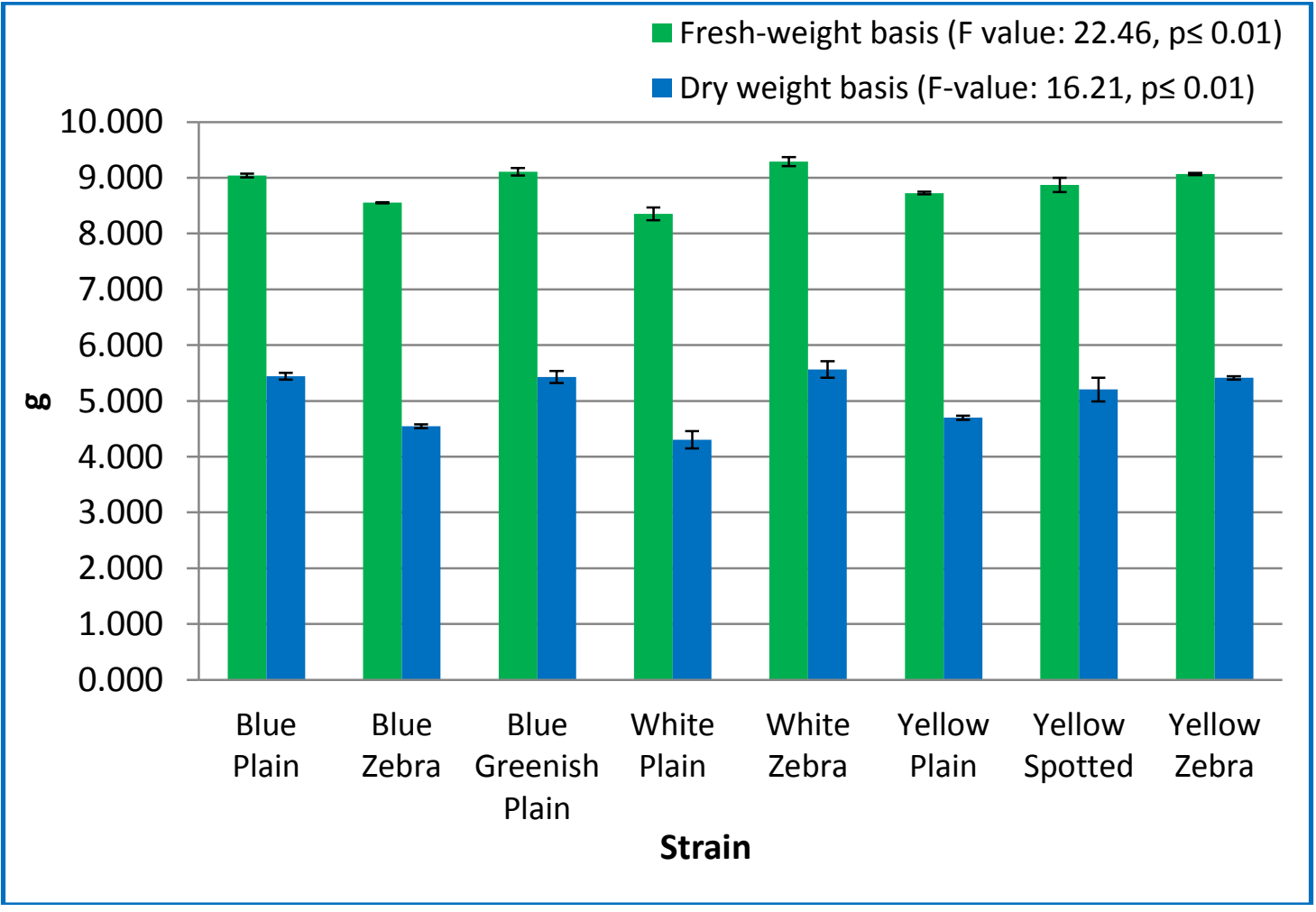

Fig. 2: Ingesta per gram of shell in selected strains of eri silkworm 


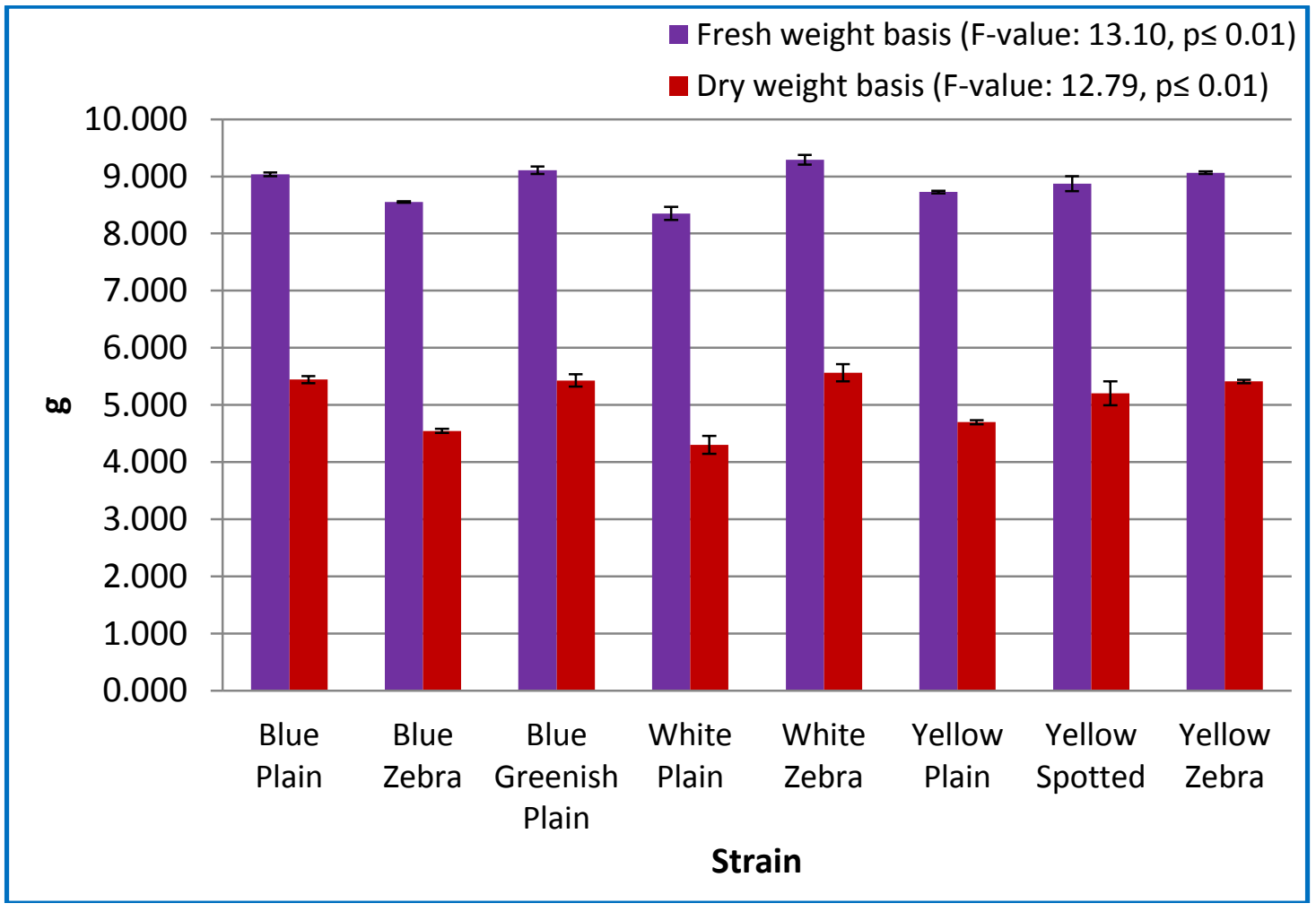

Fig. 3: Digesta per gram of shell in selected strains of eri silkworm

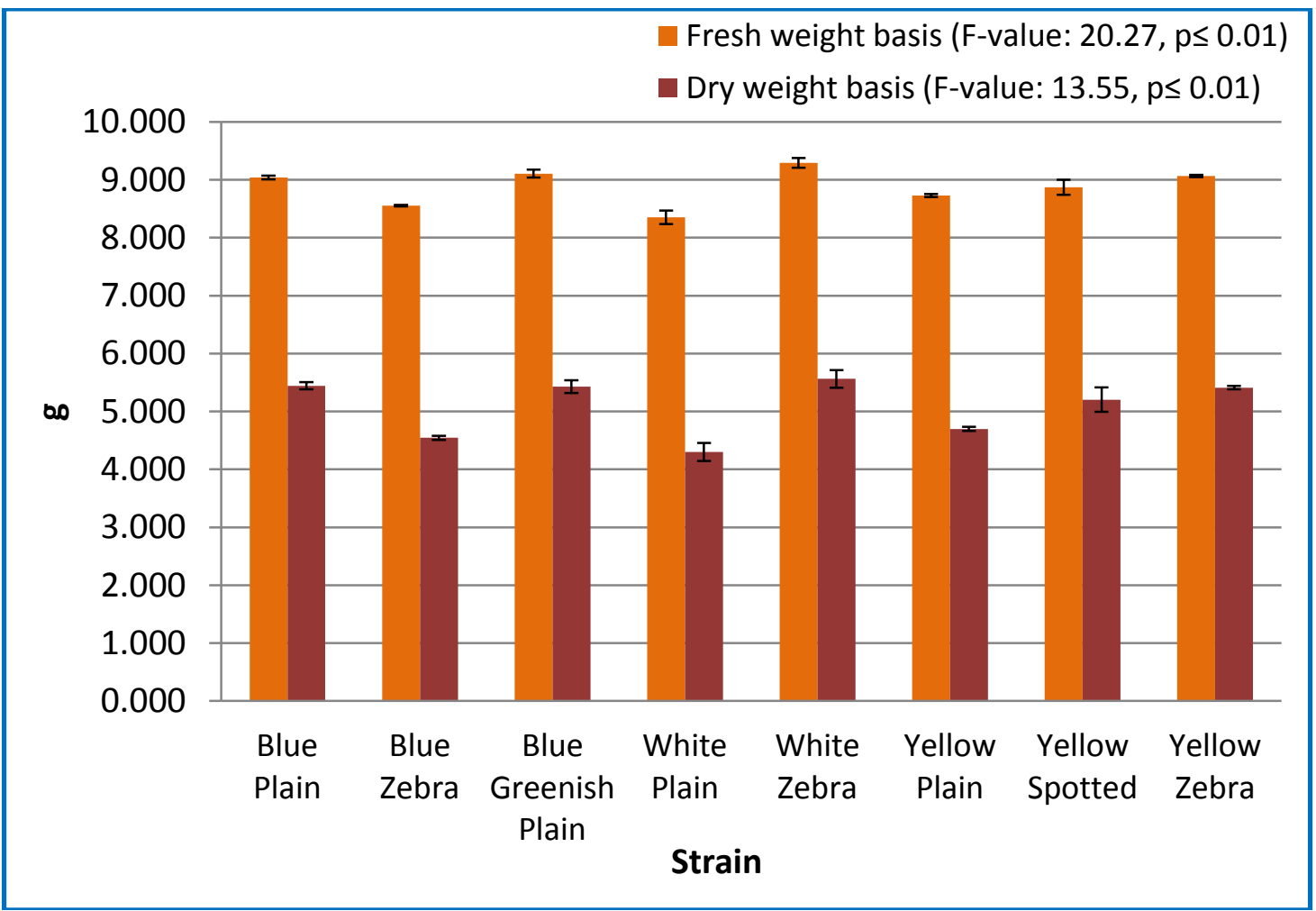


Fig. 4: Digesta per gram of shell in selected strains of eri silkworm

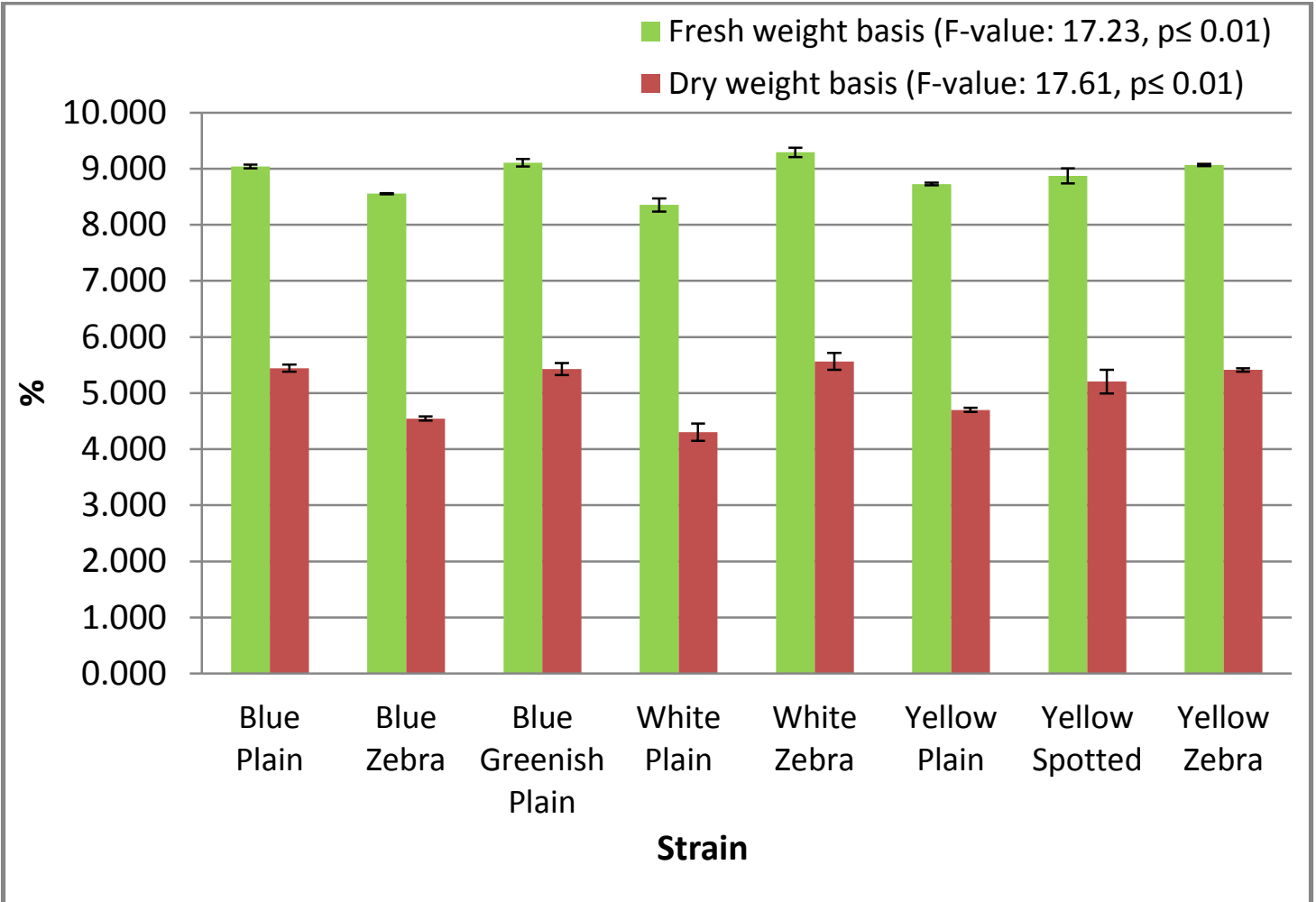

Fig. 5: Efficiency conversion of ingested food to cocoon in selected strains of eri silkworm

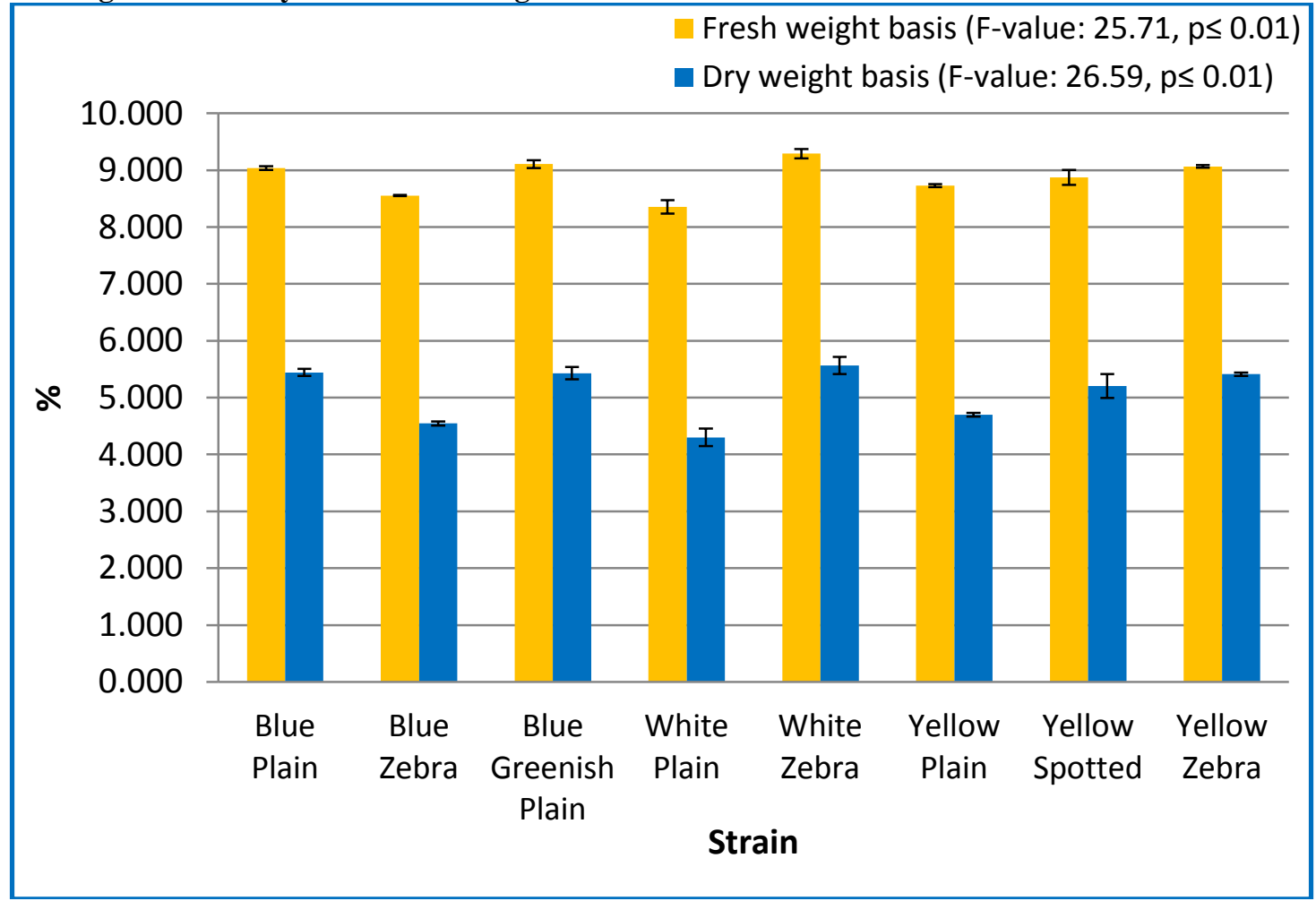


Fig. 6: Efficiency of conversion of ingested food to shell in selected strains of eri silkworm

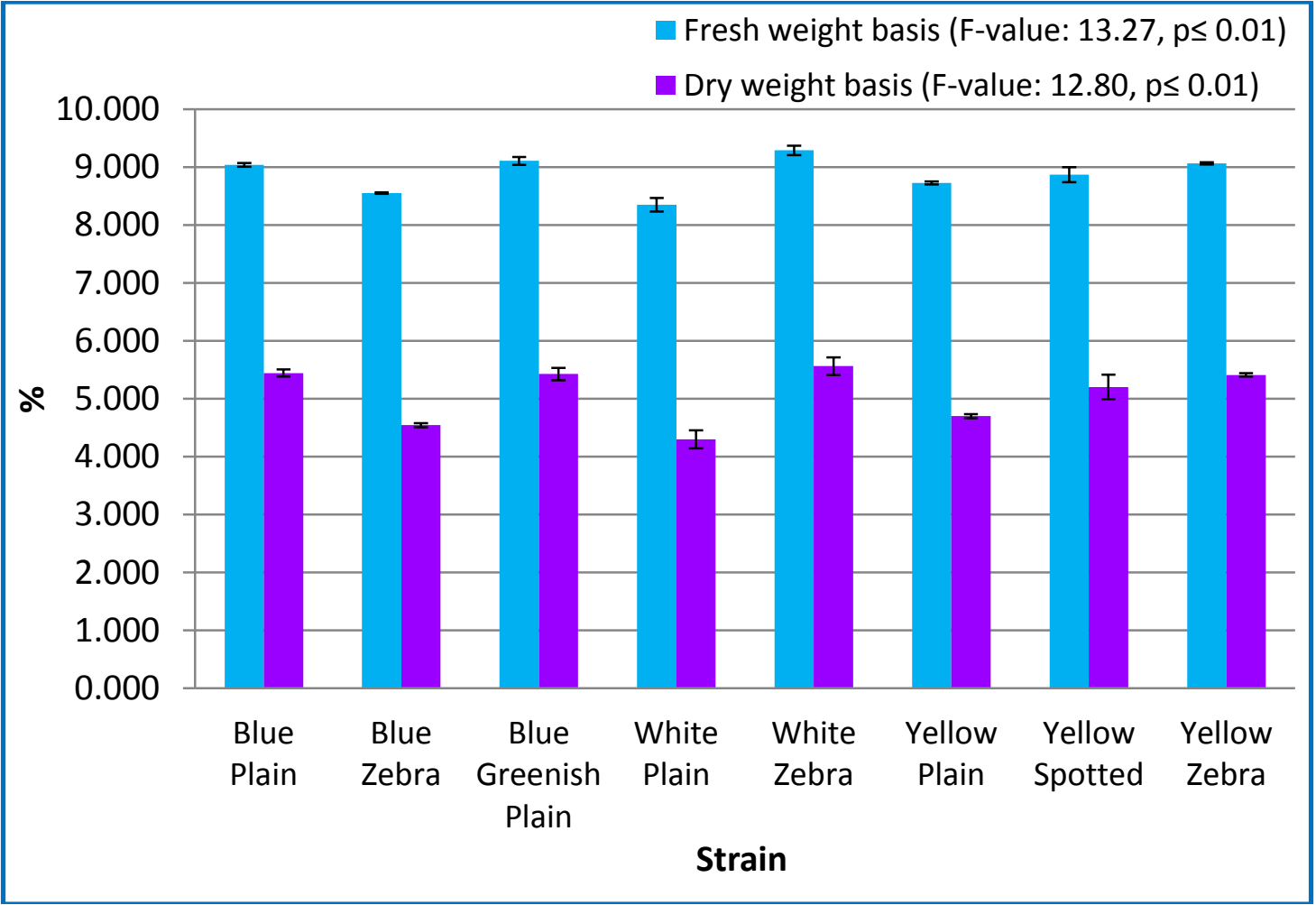

Fig. 7: Efficiency of conversion of ingested food to cocoon in selected strains of eri silkworm

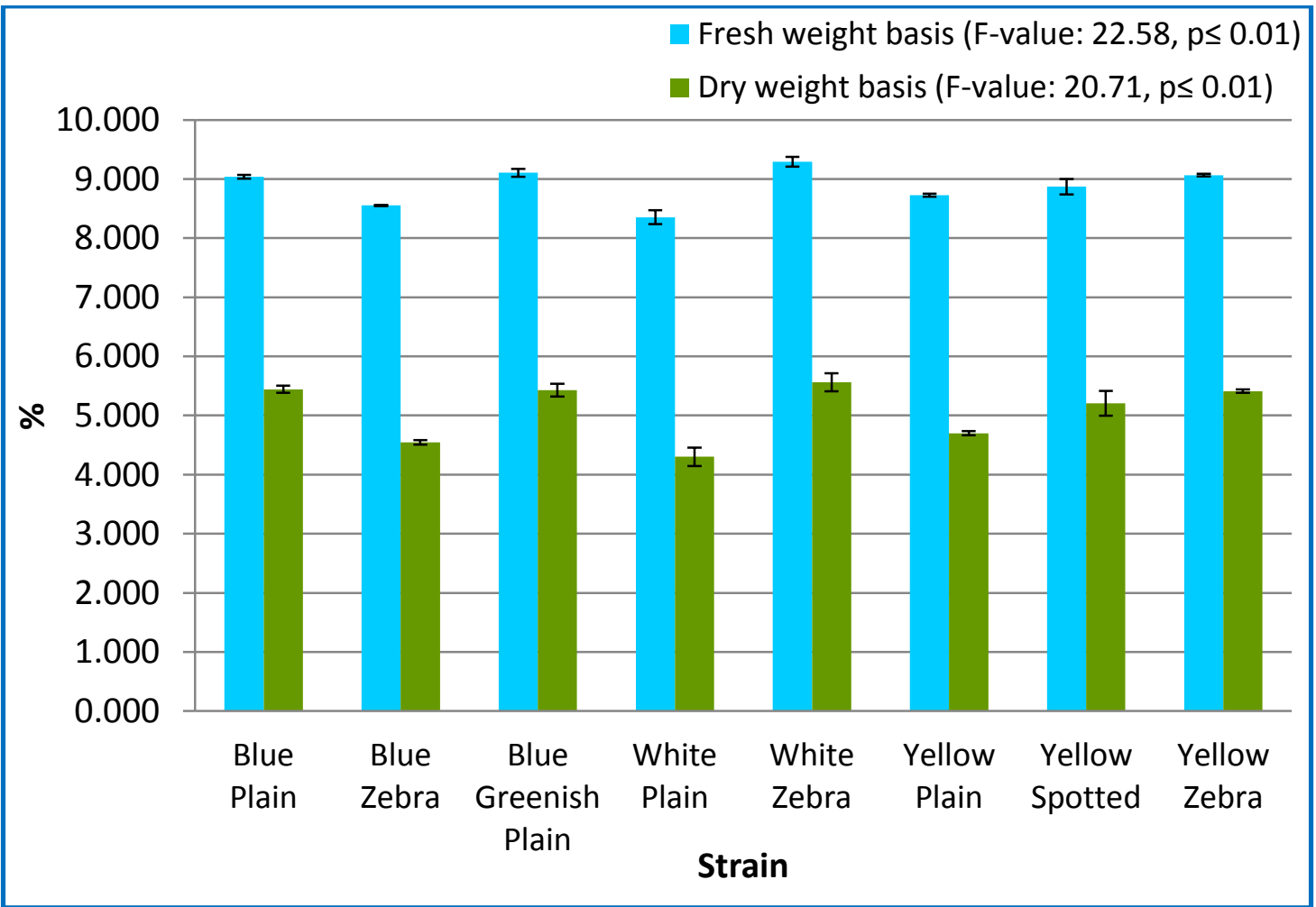


Fig. 8: Efficiency of conversion of ingested food to shell in selected strains of eri silkworm

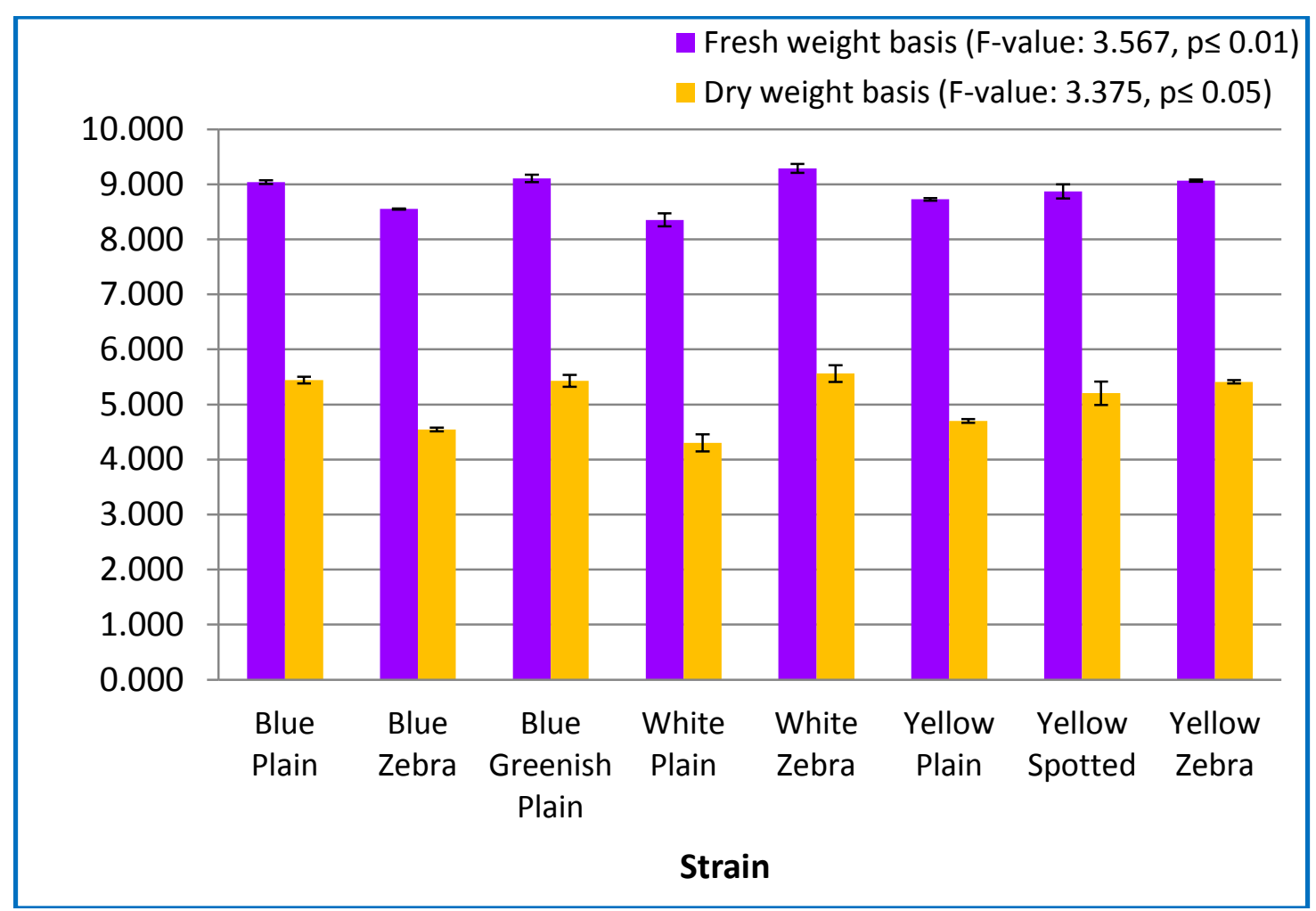

Fig. 9: Leaf to egg ratio in selected strains of eri silkworm 